\title{
Magnet-Facilitated Selection of Electrogenic Bacteria from Marine Sediment
}

\author{
Larisa Kiseleva, ${ }^{1}$ Justina Briliute, ${ }^{1}$ Irina V. Khilyas, ${ }^{1,2}$ David J. W. Simpson, ${ }^{1}$ \\ Viacheslav Fedorovich, ${ }^{1}$ M. Cohen, ${ }^{1}$ and Igor Goryanin ${ }^{1,3}$ \\ ${ }^{1}$ Biological Systems Unit, Okinawa Institute of Science and Technology, 1919-1 Tancha, Onna-son, Okinawa 904-045, Japan \\ ${ }^{2}$ Institute of Fundamental Medicine and Biology, Kazan (Volga Region) Federal University, Ulitsa, Kremlyovskaya 18, Kazan, \\ Republic of Tatarstan 420008, Russia \\ ${ }^{3}$ School of Informatics, University of Edinburgh, 10 Crichton Street, Edinburgh EH8 9AB, UK \\ Correspondence should be addressed to Igor Goryanin; goryanin@oist.jp
}

Received 8 April 2015; Revised 3 July 2015; Accepted 13 July 2015

Academic Editor: Yu Zhang

Copyright (c) 2015 Larisa Kiseleva et al. This is an open access article distributed under the Creative Commons Attribution License, which permits unrestricted use, distribution, and reproduction in any medium, provided the original work is properly cited.

\begin{abstract}
Some bacteria can carry out anaerobic respiration by depositing electrons on external materials, such as electrodes, thereby creating an electrical current. Into the anode chamber of microbial fuel cells (MFCs) having abiotic air-cathodes we inoculated microorganisms cultured from a magnetic particle-enriched portion of a marine tidal sediment, reasoning that since some external electron acceptors are ferromagnetic, electrogenic bacteria should be found in their vicinity. Two MFCs, one inoculated with a mixed bacterial culture and the other with an axenic culture of a helical bacterium isolated from the magnetic particle enrichment, termed strain HJ, were operated for $65 \mathrm{~d}$. Both MFCs produced power, with production from the mixed culture MFC exceeding that of strain HJ. Strain HJ was identified as a Thalassospira sp. by transmission electron microscopic analysis and 16S rRNA gene comparisons. An MFC inoculated with strain HJ and operated in open circuit produced $47 \%$ and $57 \%$ of the maximal power produced from MFCs inoculated with the known electrogen Geobacter daltonii and the magnetotactic bacterium Desulfamplus magnetomortis, respectively. Further investigation will be needed to determine whether bacterial populations associated with magnetic particles within marine sediments are enriched for electrogens.
\end{abstract}

\section{Introduction}

As a group, bacteria obtain electrons for respiratory metabolism from a vast range of sources and, likewise, deliver these electrons to an equally impressive array of acceptor molecules. A growing list of bacteria have been found to be electrogenic, that is, capable of reducing external solid electron acceptors. From a biotechnological standpoint electrogenic bacteria are of interest because they can efficiently oxidize compounds within the anaerobic environment of microbial fuel cells (MFCs) while creating an electrical current [1].

Among the electrogenic bacteria a variety of mechanisms are employed for reducing external electron acceptors [2]. Two types of "nanowires" have been identified by which cells can deliver electrons from cell membrane respiratory proteins: type IV pili, found in Geobacter spp., and cytochrome-containing outer membrane extensions found in
Shewanella spp. [3, 4]. Bacteria may stably associate with a solid electron acceptor surface as attached biofilms [5] or transiently by electrokinesis, a dynamic process in which bacteria cycle between depositing electrons and swimming in the vicinity of the acceptor [6]. Some bacteria are also capable of transferring electrons to external solid electron acceptors via diffusible electron carrying shuttle molecules, some of which can be exchanged between species [7]. Other unidentified mechanisms for external electron delivery almost certainly exist. Development of means to screen for and isolate electrogens would aid in the discovery of such mechanisms.

Conductive minerals (e.g., magnetite $\mathrm{Fe}_{3} \mathrm{O}_{4}$ ) confer centimeter-long conductivity to anaerobic marine sediments [8], promoting the activity of electrogens in these environments, and enabling applications such as powering of remote devices and reductive dechlorination of contaminants 
[9]. Magnetite can facilitate electron transfer from bacteria to external receptors [10], including transfer to nitratereducing bacteria [11], and under acidic conditions magnetite it can be an external electron acceptor [12]. Recently, it was demonstrated that magnetite, owing to its mixed valency, can behave as a battery, being oxidized by phototrophic bacteria in the light and reduced by electrogenic bacteria in the dark [13]. We reasoned, therefore, that electrogenic bacteria may be found in preferential association with magnetic particles of marine sediments. Here we describe the isolation and partial characterization of an electrogenic bacterium Thalassospira sp. strain $\mathrm{HJ}$ from a magnetic particle-enriched portion of a marine tidal sediment.

\section{Materials and Methods}

2.1. Sediment Sampling and Preparation. Sandy sediment from Kaichu-Doro Beach $\left(26^{\circ} 19^{\prime} 56.1^{\prime \prime} \mathrm{N}, 127^{\circ} 54^{\prime} 0^{\prime \prime} \mathrm{E}\right.$; October, 2013) Okinawa Japan, was sampled to $25 \mathrm{~cm}$ depth and placed into $500 \mathrm{~mL}$ bottles to approximately half capacity, filling the remainder of the bottle with seawater. At the laboratory, the sample was vigorously mixed and allowed to settle with a magnet pressed against the outside of the container positioned above the height of the sediment surface before mixing. After the sediment had settled, $4 \mathrm{~mL}$ of liquid and adherent magnetic particles from the region closest to the magnet was sampled with a sterile Pasteur pipette. The "capillary racetrack method" was then used to enrich for magnet-associated bacteria from the sample [14]. Fluid from the capillary was inoculated into a test tube containing $10 \mathrm{~mL}$ culture medium (Difco Marine Broth 2216) supplemented with $50 \mathrm{mg} \mathrm{L}^{-1} \mathrm{FeCl}_{3}$ (Marine-Fe broth) and grown overnight at $23^{\circ} \mathrm{C}$ without shaking. A sample was streaked to Marine-Fe Agar, incubated for $2 \mathrm{~d}$, and a resulting colony of a spiral bacterium (termed strain $\mathrm{HJ}$ ) was subcultured into Marine-Fe broth. $50 \mathrm{~mL}$ subcultures of both the original capillary racetrack-derived mixed community and strain HJ were poured into separate MFCs that were topped off with $\sim 125 \mathrm{~mL} 0.1 \mathrm{M}$ sodium/potassium phosphate buffer (pH 5.9) and $1 \mathrm{~mL} 2 \%$ sodium acetate.

\subsection{Operation of Sediment-Derived Culture-Inoculated Micro-} bial Fuel Cells. Two single-chamber, air-cathode MFCs $(H$, $10 \mathrm{~cm} ; L, 12 \mathrm{~cm} ; W, 10 \mathrm{~cm}$ ) were prepared to have internal working volume of $175 \mathrm{~mL}$. The internal MFC chamber contained two anodes (approximately $6 \times 8 \mathrm{~cm}$ ), suspended $2-3 \mathrm{~mm}$ off the bottom of the chamber, composed of a layer of $0.4 \mathrm{~mm}$ proprietary conductive carbon cloth to which $2 \mathrm{~mm}$ average size activated carbon granules were bound with conducted glue to provide more surface area. The granules had been prepared from birch precursor and pretreated with a neutral red catalyst to facilitate electron transfer. The two cathodes $(6 \times 8 \mathrm{~cm})$ were graphite plates $(3 \mathrm{~mm}$ thick; $60 \%$ porosity) sprayed on the liquid-facing side with an aqueous 5\% Fumion membrane polymer (FuMA-Tech, BietigheimBissingen, Germany) while activated carbon granules (treated with iron(II) phthalocyanine) were mechanically pressed to the air-facing side using netting frame. Unit cathode

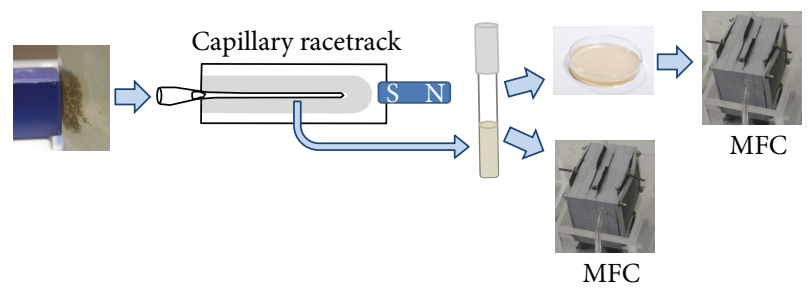

FIGURE 1: A flow scheme indicating the procedure for enrichment of magnetic particles from sediment and inoculation of marine broth medium and microbial fuel cells.

section (including membrane) was cleaned by immersion in concentrated $\mathrm{HCl}$ before module assembly for $20 \mathrm{~min}$ to remove any organics and was then soaked in sterile distilled water, with water changes every $1 \mathrm{~h}$ until the $\mathrm{pH}$ was neutralized. The reactor cell PVC surfaces were cleaned by washing with soap and water, drying, and then wiping down with acetone solvent. Anode and internal reactor areas were sprayed with $70 \%$ ethanol solution just prior to final assembly. The cathode extended into a bath containing an electrolyte solution maintained at $\mathrm{pH} 2$ with regular additions of $1 \mathrm{~N} \mathrm{HCl}$ to provide a source of protons for the abiotic reduction of oxygen to water. The MFCs were maintained on a $24 \mathrm{~h}$ open circuit/24 h closed circuit cycle, using an external resistance of $40 \Omega$. The anode and cathode electrodes were connected with a multichannel logger (Graphtec midi LOGGER GL820, Japan) for daily voltage measurements. The corresponding electric current was calculated using Ohm's law $(V=I R)$. Power density was obtained according to the equation $P=$ $I V / A$, where $I$ is the current, $V$ is the voltage, and $A$ is the projected surface area of the cathode.

Once weekly, after removal of $1 \mathrm{~mL}$ mixed contents for chemical oxygen demand (COD) analysis, the MFCs were fed with approximately $5 \mathrm{~mL}$ phosphate buffer containing $1 \mathrm{~g} \mathrm{~L}^{-1}$ sodium acetate when COD analysis indicated substrate depletion. The extra volume of the feed was needed to replace losses due to evaporation through the cathode membrane. Upon completion of the monitoring period on the 65th day of operation, due to declining power production, the MFCs were disassembled. Anode material was sampled and bacteria were isolated from the strain $\mathrm{HJ}$-inoculated MFC to confirm the presence of strain $\mathrm{HJ}$.

2.3. Bacterial Isolation and Initial Characterization. DNA from strain $\mathrm{HJ}$ was isolated and subject to genomic sequencing [15]. Phylogenetic analyses of the 16S rRNA gene (GenBank accession number KP704219) were performed using the Phylogeny.fr platform [16]. Minimum and maximum temperatures for growth were determined by culturing on Marine Agar plates. Catalase and oxidase activities were tested and Gram staining was carried out using standard microbiological methods.

2.4. Transmission Electron Microscopy. Transmission electron microscope (TEM) imaging was performed on a JEOL JEM-1230R Electron Microscope at an accelerating voltage of 

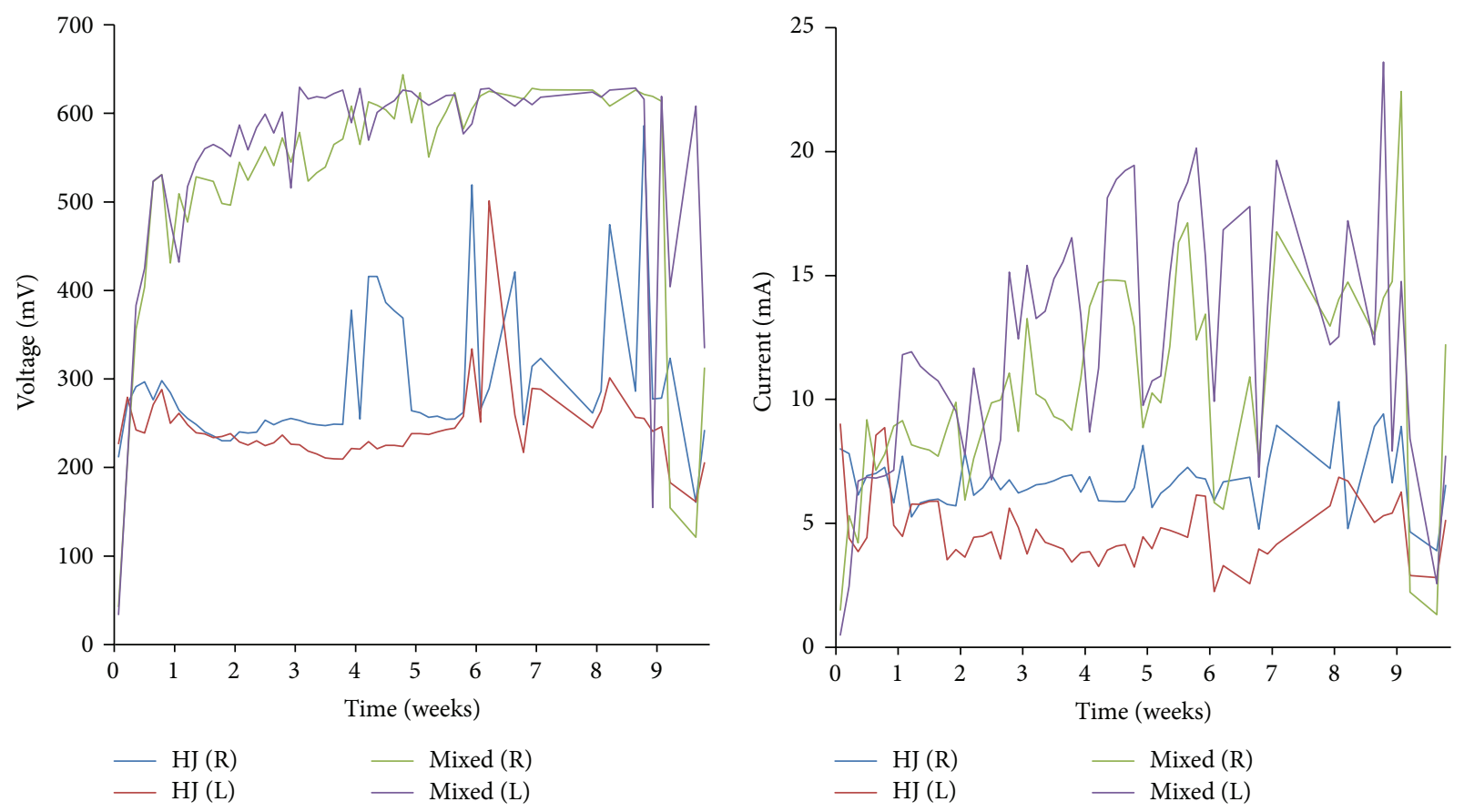

FIGURE 2: Electrical output from microbial fuel cells inoculated with cultures derived from tidal beach sediment obtained from Kaichu-Doro Beach, Okinawa, Japan. Total anode surface area, $151 \mathrm{~cm}^{2}\left(75.5 \mathrm{~cm}^{2}\right.$ per anode); $175 \mathrm{~mL}$ volume. Plotted lines indicate activity from the mixed culture-inoculated MFC and the strain HJ-inoculated MFC; R, right, and L, left anode-cathode couple.

$100 \mathrm{KV}$. Strain HJ cells were prepared from cultures grown at room temperature $\left(23^{\circ} \mathrm{C}\right)$ in $50 \mathrm{~mL}$ of Marine-Fe broth to an $\mathrm{OD}_{600}$ of 1.0 . The pelleted cells were fixed with $1 \%$ osmium tetroxide in $0.1 \mathrm{M}$ cacodylate buffer $(\mathrm{pH}=7.2)$ for $30 \mathrm{~min}$ and washed with water three times for $5 \mathrm{~min}$. A drop of fixed bacterial cells was deposited onto a carbon-coated HF34 200 mesh copper grid, washed once with distilled water, and stained for 3 to $5 \mathrm{sec}$ with $1 \%$ uranyl acetate.

2.5. Inoculation and Monitoring of Microbial Fuel Cells Inoculated with Axenic Bacterial Cultures. A micro-MFC array was developed from two parts of Plexiglas with three $4 \mathrm{~cm}$ microchambers to test for current generation by three axenic bacterial cultures. Each chamber consisted of an anode and a cathode compartment ( $8 \mathrm{~mm}$ deep) separated by a cationexchange membrane Nafion $117\left(19.6 \mathrm{~cm}^{2}\right.$; DuPont Co., Delaware USA). The anode and cathode electrodes $(3 \mathrm{~mm}$ thick graphite plates; $45-50 \%$ porosity, Xinghe County Muzi Carbon Co., Ltd, China) were connected with a multichannel logger (Graphtec midi LOGGER GL820, Japan) for daily voltage measurements. $1 \mathrm{~mm}$ thick rubber gaskets were used for sealing between the anode and cathode compartments. A titanium screw held the electrode against the membrane and acted as electrical connector. Each micro-MFC chamber was equipped with a $2.5 \mathrm{ID} \mathrm{mm}$ polyurethane inlet tube (FESTO, Germany) on the bottom for medium and electrolyte feeding and one on the top for biogas output and replacement of exhausted electrolyte. For disinfection the plexiglas microchambers were soaked in a $10 \%$ bleach solution, rinsed with deionized water, and then exposed to
UV light for $12 \mathrm{~h}$. Graphite plates were washed with $100 \%$ isopropanol in an ultrasonic bath and then heated in an oven for $2 \mathrm{~h}$ at $200 \mathrm{C}$. Micro-MFCs were operated in the open circuit mode and current measurements were performed every 24 hours starting from time of inoculation. $50 \mathrm{mM}$ iron(II) phthalocyanine, without $\mathrm{N}_{2}$ sparging, was used as the cathode electrolyte solution.

Axenic bacterial cultures (Thalassospira sp. HJ, the known electrogen Geobacter daltonii, and the magnetotactic Desulfamplus magnetomortis) were pregrown with shaking at $37^{\circ} \mathrm{C}$ for $12 \mathrm{~h}$ in $5 \mathrm{~mL}$ of modified PBS medium containing (per liter) $4.58 \mathrm{~g} \mathrm{Na}_{2} \mathrm{HPO}_{4}, 2.45 \mathrm{~g} \mathrm{NaH}_{2} \mathrm{PO}_{4} \cdot \mathrm{H}_{2} \mathrm{O}, 0.31 \mathrm{~g} \mathrm{NH} \mathrm{Nl}_{4} \mathrm{Cl}$, $0.13 \mathrm{~g} \mathrm{KCl}, 5 \mathrm{~g}$ glucose, $5 \mathrm{~g}$ yeast extract, and $5 \mathrm{~g}$ peptone. Bacterial cells were harvested, washed with $16 \mathrm{mM}$ phosphate buffer ( $\mathrm{pH}$ 7.0), and resuspended into $50 \mathrm{~mL}$ fresh modified PBS medium. The initial cell concentration was adjusted to an optical density at $600 \mathrm{~nm}$ of 0.3 as measured by a Spectronic GENESYS 5 spectrophotometer (Milton Roy Company, Rochester, NY, USA) with filtered cell-free culture medium as reference.

The micro-MFCs were inoculated initially with $15 \mathrm{~mL}$ medium containing bacterial cells (exceeding the $\sim 10 \mathrm{~mL}$ volume of the anode chamber since the porous graphite absorbed some liquid). Bacteria-free modified PBS medium containing $0.1 \% \mathrm{NaN}_{3}$ was used for control experiments. All experiments were set up in two technical replications and two biological replications. The axenicity of the anolytes for the strain HJ-containing MFCs was determined at the end of the experiments by plating serial dilutions to Marine Agar medium. Experiments were performed at room temperature. 


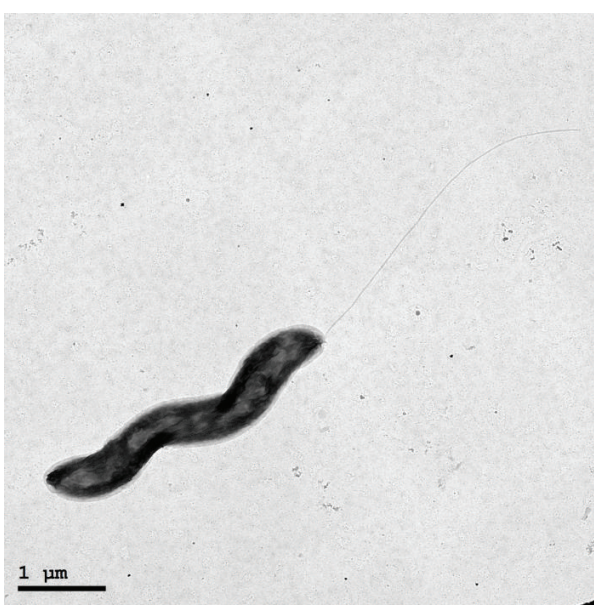

(a)

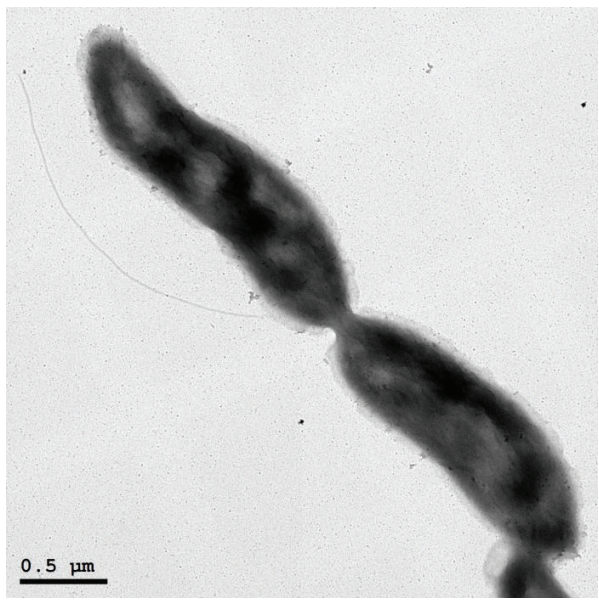

(c)

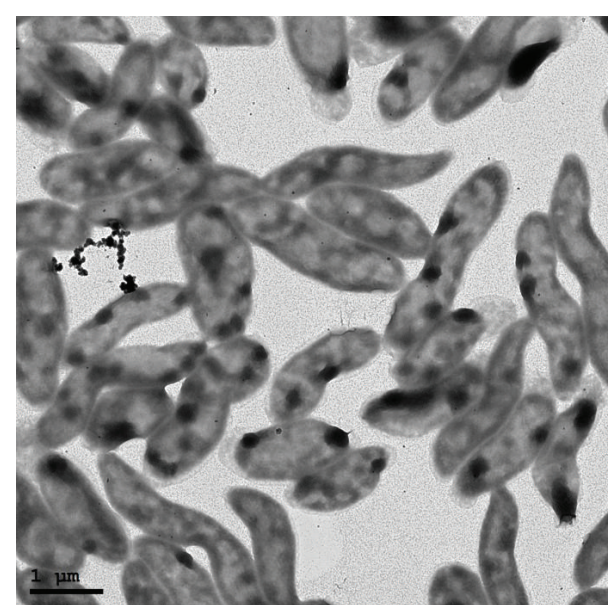

(b)

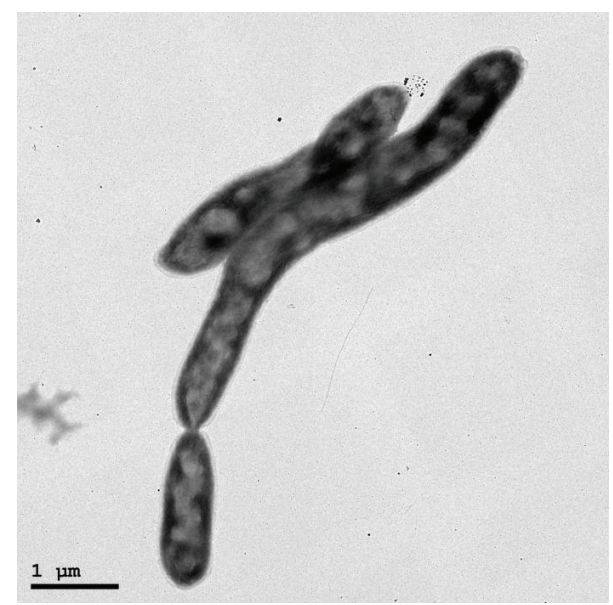

(d)

Figure 3: Transmission electron micrographs of Thalassospira sp. strain HJ showing various features. (a) A single polar flagellum; (b) intracellular electron-dense regions; (c) symmetric cell division; and (d) asymmetric cell division. Representative images are shown.

\section{Results and Discussion}

To obtain magnetic particle-associated bacteria, some of which should be electrogenic [12], we subjected tidal beach sediment to the enrichment procedure depicted in Figure 1. One MFC was inoculated with a mixed culture derived from the magnetic particle-enriched sediment and the other with an axenic culture of a helical bacterium, strain HJ, isolated from the enriched sediment. Both MFCs were found to produce power, with the current and voltage generated from the mixed culture MFC being substantially higher (Figure 2). The comparatively low power density observed of strain $\mathrm{HJ}$ is typical of axenic bacterial cultures relative to that of the communities from which they are derived [5]. At the end of the experiment strain $\mathrm{HJ}$ was reisolated from the MFC to confirm its retention.

Strain HJ was identified by means of microscopic analysis (Figure 3) and 16S rRNA gene sequence comparisons (Figure 4) to be of the genus Thalassospira. TEM images show cells of $0.5-0.7 \mu \mathrm{m}$ width and $1.5-5.7 \mu \mathrm{m}$ length having single polar flagella typical of the genus Thalassospira [17], with evidence of both symmetric and asymmetric cell division (Figure 3). One or more electron-dense staining regions can be seen within most cells (Figure 3). Cells were motile, stained Gram negative, and tested positive for catalase and oxidase activity. Growth occurred on Marine Agar at temperatures ranging from $12^{\circ} \mathrm{C}$ to $39^{\circ} \mathrm{C}$ and $\mathrm{pH}$ values ranging from 5.5 to 10.5 . The closest matching $16 \mathrm{~S}$ rRNA gene sequence to a named species within the GenBank database was that of Thalassospira profundimaris strain WP0211 (1449/1453, 99.7\% identity), which notably differs from strain $\mathrm{HJ}$ in its lack of flagella [18].

Micro-MFC chambers inoculated with axenic cultures of Thalassospira sp. strain HJ and, for comparison, Geobacter daltonii and Desulfamplus magnetomortis showed electrical current production immediately after inoculation but differed in the intensity and shape of the subsequent production curve (Figure 5). Thalassospira sp. strain HJ and D. magnetomortis displayed gradual increases in current after initiation whereas current production from $G$. daltonii decreased 


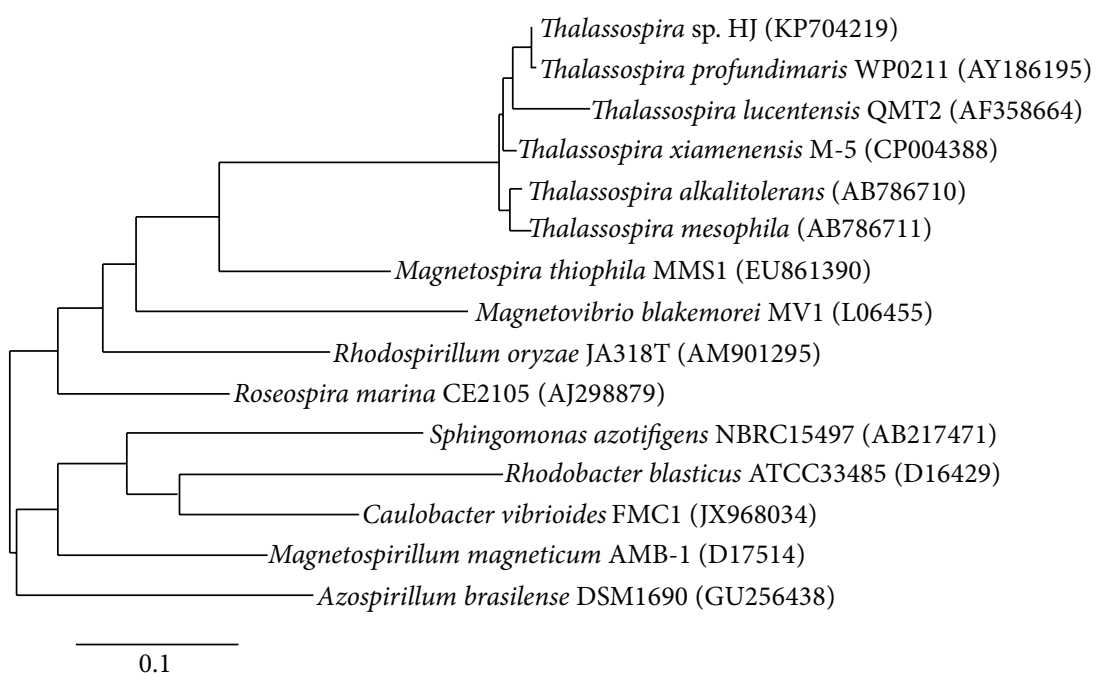

FIGURE 4: Phylogenetic tree of strain HJ and selected alphaproteobacteria based on 16S rRNA gene sequences. The tree was constructed from sequences aligned by MUSCLE using maximum-likelihood method of PhyML 3.0 [16, 21]. The scale bar reflects evolutionary distance, measured in units of substitution per nucleotide site.
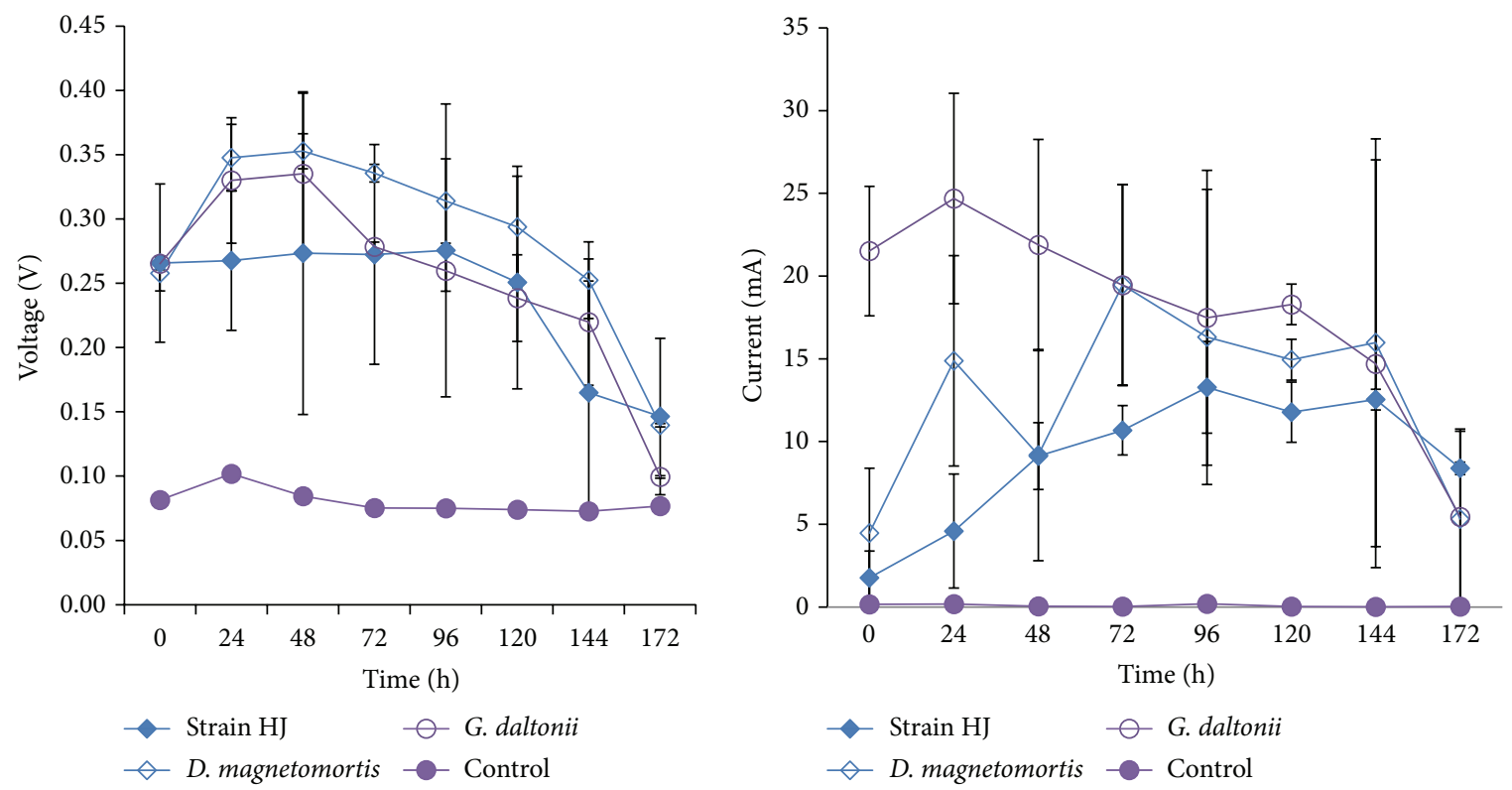

FIGURE 5: Voltage and current readings ( \pm range; $n=2$ ) from microbial fuel cells inoculated with axenic cultures of Thalassospira sp. strain $\mathrm{HJ}$, Geobacter daltonii, and Desulfamplus magnetomortis or medium only with $1 \mathrm{~g} \mathrm{~L}^{-1}$ sodium azide (control). Anode surface area, $19.6 \mathrm{~cm}^{2}$; $10 \mathrm{~mL}$ volume.

with time. After $172 \mathrm{~h}$, the current for all axenic cultures decreased to $5-8 \mathrm{~mA}$, which was attributed with C-source depletion. Voltage drop was observed after $144 \mathrm{~h}$ from the strain HJ-inoculated micro-MFC, whereas G. daltonii and D. magnetomortis MFCs demonstrated voltage loss after $48 \mathrm{~h}$. As a control, to determine the contribution of growth medium components to current and voltage production, a micro-MFC was filled with sterile medium. Although there was no observable current generation background voltage was observed (Figure 5). The maximal single-value power readings from the micro-MFCs were of $2.6 \mathrm{~W} \mathrm{~m}^{-2}$ (at $96 \mathrm{~h}$ ) for Thalassospira sp. strain HJ, $5.5 \mathrm{~W} \mathrm{~m}^{-2}$ (at $144 \mathrm{~h}$ ) for $D$. magnetomortis, and $4.6 \mathrm{~W} \mathrm{~m}^{-2}$ (at $24 \mathrm{~h}$ ) for G. daltonii.

Geobacter is a well-characterized genus of electrogenic bacteria and although we are not aware of prior reports of electrogenicity by the magnetotactic bacterium $D$. magnetomortis members of sulfate-reducing members of the Deltaproteobacteria, to which D. magnetomortis belongs, were found to display transcriptomic responses to changes in MFC electrode potential indicative of electrogenic behavior [19]. We hypothesize that magnetosomes could confer a selective benefit by enabling bacteria to hone in on ferromagnetic 
external electron acceptors. A wider survey of magnetotactic bacteria for electrogenicity would be warranted.

Recently, two marine sediment-derived Thalassospira sp. isolates were reported to exhibit electrotrophic behavior, accepting electrons from insoluble sulfur [20] but the capacity of these strains to transfer electrons to an anode as we have found here of Thalassospira sp. strain HJ was not examined. Examination of the strain $\mathrm{HJ}$ genome does not reveal any homologs for the pili or outer membrane extension-type external electron transfer systems found in Geobacter or Shewanella species [15], and microscopic imaging of anodes from strain HJ-colonized MFCs implies that biofilm formation is not necessary for electrogenicity (data not shown). Thus, we hypothesize that external electron transfer occurs via an electron shuttle-type mechanism.

\section{Conclusions}

A microbial community derived from magnetic particleenriched marine sediment displayed electrogenic behavior and yielded an electrogenic bacterium identified to be a Thalassospira species. This is the first report of electrogenic behavior within the genus Thalassospira. A more extensive study would be needed to determine whether the proportion of electrogenic bacteria obtained from this magnetic particle enrichment procedure exceeds that found in the environment. With their diurnal patterns of flooding and diversity of mineral components tidal sediments should be rich environments to bioprospect for electrogenic bacteria.

\section{Conflict of Interests}

The authors declare that there is no conflict of interests regarding the publication of this paper.

\section{Acknowledgments}

Funding was provided by the Okinawa Institute of Science and Technology. I. V. Khilyas was supported by Russian Government Program of Competitive Growth of Kazan Federal University. The authors thank M Power World, Ltd., for consultations and provision of equipment and T. Sasaki for conducting transmission electron microscopy.

\section{References}

[1] V. Gude, B. Kokabian, and V. Gadhamshetty, "Beneficial bioelectrochemical systems for energy, water, and biomass production," Journal of Microbial \& Biochemical Technology, vol. 6, article 005, p. 2, 2013.

[2] S. A. Patil, C. Hägerhäll, and L. Gorton, "Electron transfer mechanisms between microorganisms and electrodes in bioelectrochemical systems," Bioanalytical Reviews, vol. 4, no. 2-4, pp. 159-192, 2012.

[3] D. R. Lovley and N. S. Malvankar, "Seeing is believing: Novel imaging techniques help clarify microbial nanowire structure and function," Environmental Microbiology, vol. 17, no. 7, pp. 2209-2215, 2015.
[4] S. Pirbadian, S. E. Barchinger, K. M. Leung et al., "Shewanella oneidensis MR-1 nanowires are outer membrane and periplasmic extensions of the extracellular electron transport components," Proceedings of the National Academy of Sciences of the United States of America, vol. 111, no. 35, pp. 12883-12888, 2014.

[5] B. E. Logan, "Exoelectrogenic bacteria that power microbial fuel cells," Nature Reviews Microbiology, vol. 7, no. 5, pp. 375-381, 2009.

[6] H. W. Harrisa, M. Y. El-Naggarb, O. Bretschgerc et al., "Electrokinesis is a microbial behavior that requires extracellular electron transport," Proceedings of the National Academy of Sciences of the United States of America, vol. 107, no. 1, pp. 326331, 2010.

[7] K. Rabaey, N. Boon, M. Höfte, and W. Verstraete, "Microbial phenazine production enhances electron transfer in biofuel cells," Environmental Science \& Technology, vol. 39, no. 9, pp. 3401-3408, 2005.

[8] N. S. Malvankar, G. M. King, and D. R. Lovley, "Centimeterlong electron transport in marine sediments via conductive minerals," The ISME Journal, vol. 9, no. 2, pp. 527-531, 2015.

[9] D. R. Lovley and K. P. Nevin, "A shift in the current: new applications and concepts for microbe-electrode electron exchange," Current Opinion in Biotechnology, vol. 22, no. 3, pp. 441-448, 2011.

[10] F. Liu, A. Rotaru, P. M. Shrestha, N. S. Malvankar, K. P. Nevin, and D. R. Lovley, "Magnetite compensates for the lack of a pilin-associated $c$-type cytochrome in extracellular electron exchange," Environmental Microbiology, vol. 17, no. 3, pp. 648655, 2015.

[11] S. Kato, K. Hashimoto, and K. Watanabe, "Microbial interspecies electron transfer via electric currents through conductive minerals," Proceedings of the National Academy of Sciences of the United States of America, vol. 109, no. 25, pp. 10042-10046, 2012.

[12] J. E. Kostka and K. H. Nealson, "Dissolution and reduction of magnetite by bacteria," Environmental Science \& Technology, vol. 29, no. 10, pp. 2535-2540, 1995.

[13] J. M. Byrne, N. Klueglein, C. Pearce, K. M. Rosso, E. Appel, and A. Kappler, "Redox cycling of Fe(II) and Fe(III) in magnetite by Fe-metabolizing bacteria," Science, vol. 347, no. 6229, pp. 14731476, 2015.

[14] R. S. Wolfe, R. K. Thauer, and N. Pfennig, "A 'capillary racetrack' method for isolation of magnetotactic bacteria," FEMS Microbiology Letters, vol. 45, no. 1, pp. 31-35, 1987.

[15] L. Kiseleva, S. K. Garushyants, J. Briliute, D. J. Simpson, M. F. Cohen, and I. Goryanin, "Genome sequence of the electrogenic petroleum-degrading Thalassospira sp. strain HJ," Genome Announcements, vol. 3, no. 3, Article ID e00483-15, 2015.

[16] A. Dereeper, V. Guignon, G. Blanc et al., "Phylogeny.fr: robust phylogenetic analysis for the non-specialist," Nucleic Acids Research, vol. 36, supplement 2, pp. W465-W469, 2008.

[17] J. I. Baldani, S. S. Videira, J. I. Baldani et al., "The family Rhodospirillaceae," in The Prokaryotes, E. Rosenberg, E. DeLong, S. Lory, E. Stackebrandt, and F. Thompson, Eds., pp. 533-618, Springer, Berlin, Germany, 2014.

[18] C. Liu, Y. Wu, L. Li, M. Yingfei, and Z. Shao, "Thalassospira xiamenensis sp. nov. and Thalassospira profundimaris sp. nov," International Journal of Systematic and Evolutionary Microbiology, vol. 57, no. 2, pp. 316-320, 2007. 
[19] S. Ishii, S. Suzuki, T. M. Norden-Krichmar et al., "A novel metatranscriptomic approach to identify gene expression dynamics during extracellular electron transfer," Nature Communications, vol. 4, article 1601, 2013.

[20] A. R. Rowe, P. Chellamuthu, B. Lam, A. Okamoto, and K. H. Nealson, "Marine sediments microbes capable of electrode oxidation as a surrogate for lithotrophic insoluble substrate metabolism," Frontiers in Microbiology, vol. 5, article 784, 2015.

[21] S. Guindon, J.-F. Dufayard, V. Lefort, M. Anisimova, W. Hordijk, and O. Gascuel, "New algorithms and methods to estimate maximum-likelihood phylogenies: assessing the performance of PhyML 3.0," Systematic Biology, vol. 59, no. 3, pp. 307-321, 2010. 

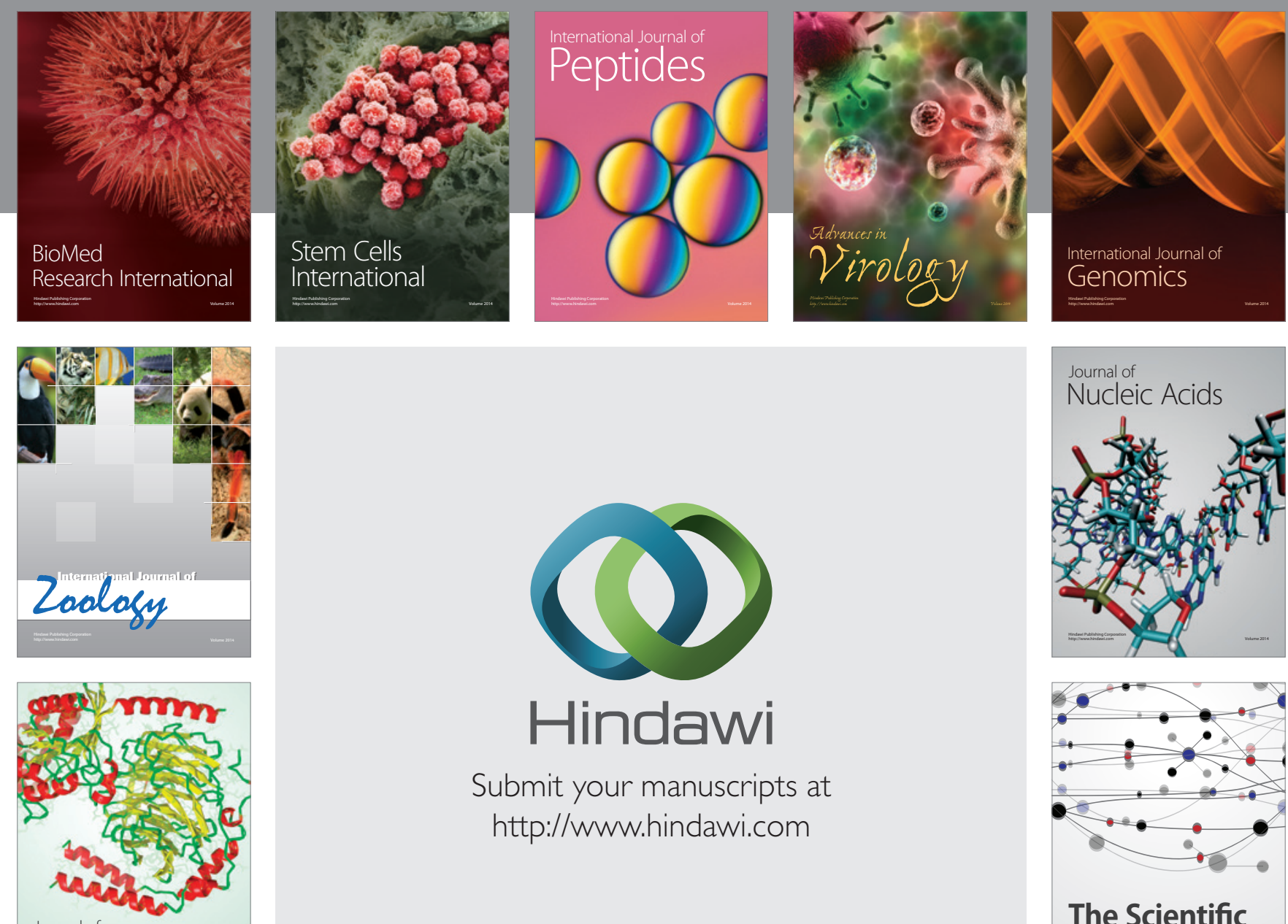

Submit your manuscripts at

http://www.hindawi.com

Journal of
Signal Transduction
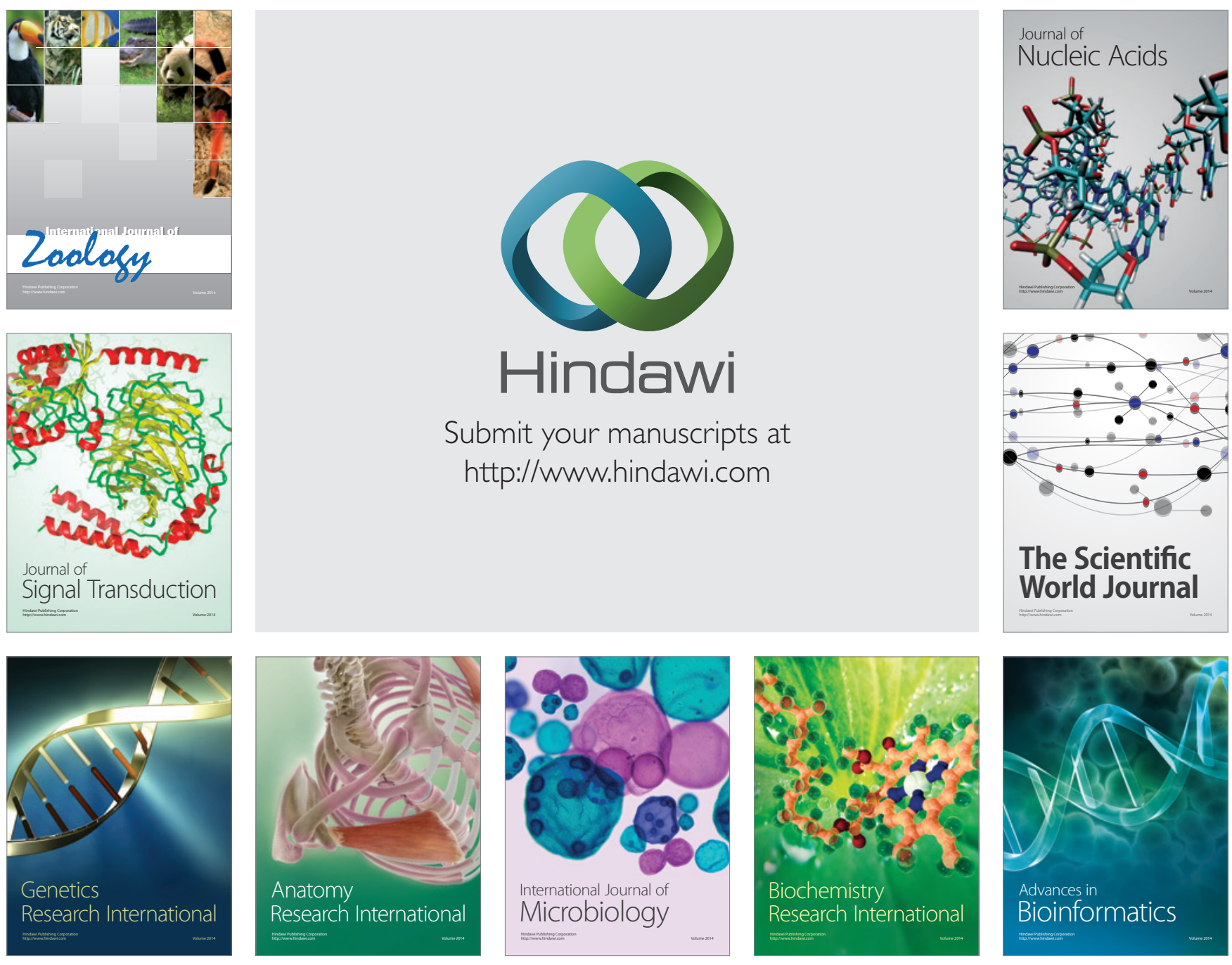

The Scientific World Journal
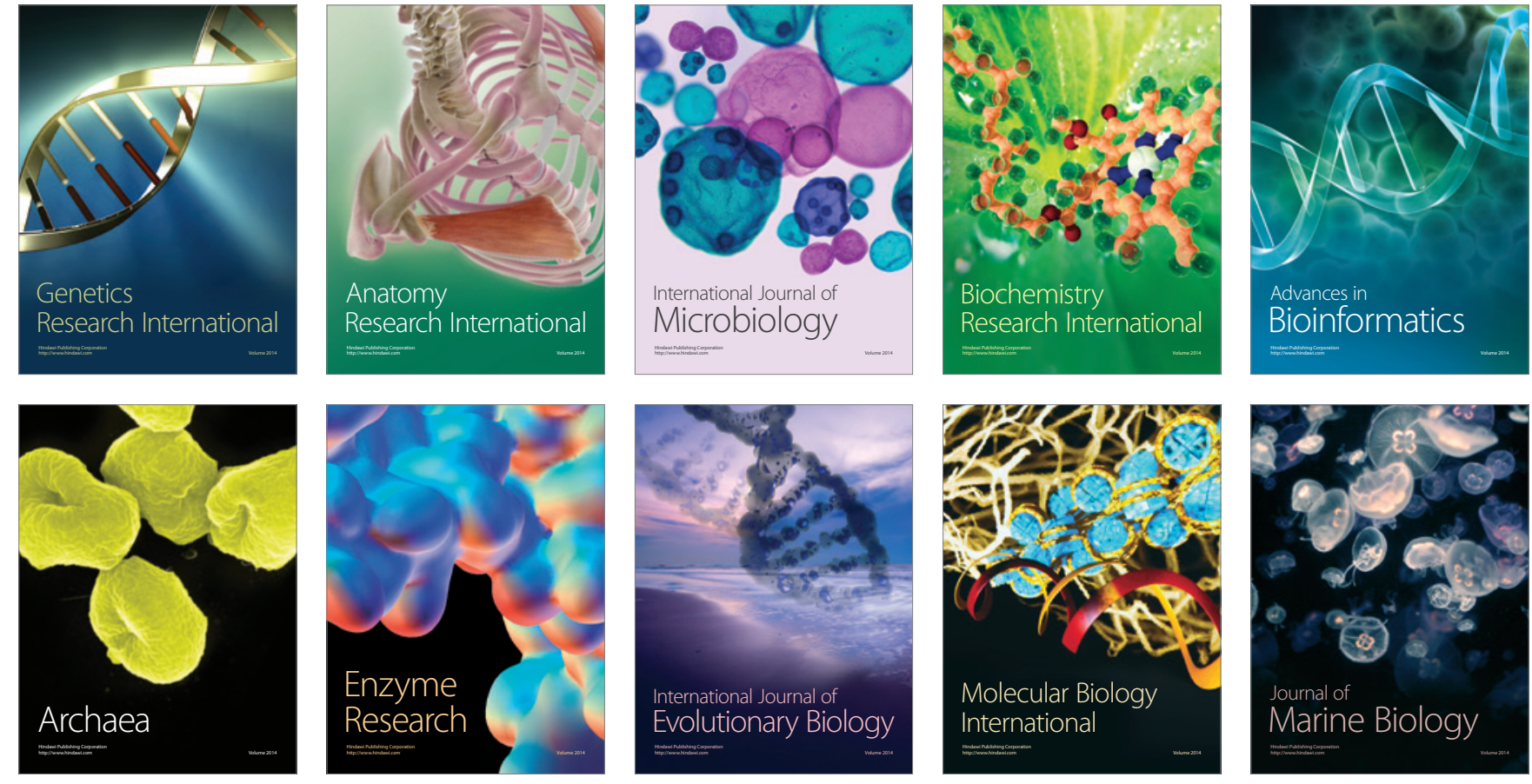